\title{
Skeletal muscle morphology and capillarization of renal failure patients receiving different dialysis therapies
}

\author{
Giorgos K. SAKKAS*, Derek BALL*, Anthony J. SARGEANT*†, \\ Thomas H. MERCER*, Pelagia KOUFAKI* and Patrick F. NAISH $\ddagger$ \\ *Centre for Biophysical and Clinical Research into Human Movement, Manchester Metropolitan University, Alsager ST7 2HL, \\ U.K., fInstitute for Fundamental and Clinical Human Movement Sciences, Vrije University, Amsterdam, The Netherlands, \\ and $\ddagger$ Directorate of Renal Medicine, North Staffordshire Hospital Trust, Staffordshire ST4 7LN, U.K.
}

\section{A}

\begin{abstract}
The morphology of gastrocnemius muscles was examined in RFPs (renal failure patients) being treated using HD (haemodialysis) and CAPD (continuous ambulatory peritoneal dialysis). RFPs $(n=24)$ volunteered to participate in the present study. Twelve RFPs (five women and seven men; mean age, 55 years) were undergoing CAPD treatment and 12 RFPs (two women and ten men; mean age, 62 years) were undergoing HD treatment. Muscle biopsies from gastrocnemius muscles were found not to differ $(P>0.05)$ in fibre type distribution, MyHC (myosin heavy chain) expression or fibre CSA (cross-sectional area) between the two groups. There were, however, significant differences $(P<0.05)$ in $C C / F$ (capillary contact/fibre), C/F (capillary to fibre ratio) and cytochrome $c$ oxidase activity. The HD group had $33 \%$ more $C C / F$, with a $19 \%$ higher $\mathrm{C} / \mathrm{F}$ and $33 \%$ greater cytochrome $\mathrm{c}$ activity in glycolytic fibres (II) than the CAPD group. There were no apparent differences in age, gender, co-morbidity, self-reported physical activity or physical functioning between the two groups, which could account for the difference in muscle capillarity between the groups. The HD patients were, however, administered heparin as a routine part of the dialysis therapy. The possibility is discussed that heparin in combination with mild anaemia and acidosis may have augmented angiogenesis in the HD patients.
\end{abstract}

\section{INTRODUCTION}

Renal failure may be treated with HD (haemodialysis), peritoneal dialysis and renal transplantation. The most common treatment modalities are HD and CAPD (continuous ambulatory peritoneal dialysis), but they differ in terms of technique and function [1]. However, studies examining the effect of dialysis treatment modality on several biochemical factors have shown that HD and CAPD have a similar effect on overall mortality and morbidity levels, particularly when co-morbid illness and acuity of onset of renal failure are taken into consideration [1].

One of the differences between the two dialysis modes is the fluctuation of toxins in the body. CAPD patients maintain a more constant level of uraemic toxins (dialysis

Key words: anaemia, capillary, continuous ambulatory peritoneal dialysis (CAPD), gastrocnemius muscle, haemodialysis, heparin, renal failure.

Abbreviations: $\mathrm{CAPD}$, continuous ambulatory peritoneal dialysis; $\mathrm{CC} / \mathrm{F}$, capillary contact $/ \mathrm{fibre} ; \mathrm{CD} / \mathrm{mm}^{2}$, capillary density $/ \mathrm{mm}^{2}$ of muscle tissue; C/F, capillary to fibre ratio; CSA, cross-sectional area; DD, diffusion distance; HD, haemodialysis; ICD, intercapillary distance; IU, international units; MyHC, myosin heavy chain; PTH, parathyroid hormone; RFP, renal failure patient; SGA, subjective global assessment; STS-5, five sit-to-stand-to-sit cycles; STS-60, sit-to-stand cycles achieved in 60 s; VEGF, vascular endothelial growth factor.

Correspondence: Dr Giorgos K. Sakkas, present address, Department of Medicine University of California, San Francisco, San Francisco General Hospital, 1001 Potrero Avenue, San Francisco, CA 94110, U.S.A. (email gsakkas@itsa.ucsf.edu). 
every $4 \mathrm{~h}$ ), whereas HD patients go from very low levels on post-dialysis to very high ones at pre-dialysis (three times a week). Moreover, CAPD treatment provides patients with more freedom and independent lifestyle than $\mathrm{HD}$, which requires patients to spend at least $12 \mathrm{~h}$ a week on a dialysis unit.

It would seem logical therefore to assume that, as a consequence of the greater opportunity for physical activity, CAPD patients would have a better preserved exercise capacity and muscle morphology. However, previous studies have been unable to show differences between CAPD and HD patients in the performance of exercise tests [2]. In these studies, no measurements were made of muscle morphology, although it is well known that chronic and end-stage RFPs (renal failure patients) suffer from muscular atrophy and myopathy-neuropathy symptoms [3-6].

Therefore the aim of the present study was to examine the morphometric and morphological characteristics of the gastrocnemius muscle of RFPs undergoing CAPD and HD treatments. We hypothesized that, due to the differences in treatment for renal failure, those patients receiving HD would have smaller muscle fibres and a reduced muscle capillarization compared with those patients receiving CAPD, due to the constraints described previously.

\section{METHODS}

\section{Patient characteristics and dialysis regimens}

Patients $(n=24)$ with end-stage renal disease participated in the present study. Twelve patients [five women and seven men; mean (range) age, 55 (37-70) years, and mean (range) mass, $79(51-105) \mathrm{kg}$ ] were recruited from the CAPD unit and 12 patients [two women and ten men; mean (range) age, 62 (35-76) years, and mean (range) mass, $75(60-90) \mathrm{kg}$ ] were recruited from the HD unit.

The patients had required regular dialysis treatment on average for 47 months (range, 7-196 months) for the CAPD group and 47 months (range, 6-192 months) for the HD group.

The CAPD patients received, during the day, $4 \times$ 2 -litre exchanges with a 1.36 or $3.86 \%$ glucose concentration. The dialysis prescription is based on either $3 \times$ $1.36 \%$ plus $1 \times 3.86 \%$ ( $3: 1$ regimen) or $2 \times 1.36 \%$ plus $2 \times 3.86 \%$ (2:2 regimen). The peritoneal dialysis fluid consisted of $5.38 \mathrm{~g} / \mathrm{l} \mathrm{NaCl}, 4.48 \mathrm{~g} / \mathrm{l}$ sodium lactate, $0.184 \mathrm{~g} / \mathrm{l} \mathrm{CaCl}_{2}$ and $0.051 \mathrm{~g} / \mathrm{l} \mathrm{MgCl}$.

$\mathrm{HD}$ was performed three times/week for $4 \mathrm{~h}$ per session, using standard dialysates containing $2.0 \mathrm{~g} /$ glucose and a $1.8 \mathrm{~m}^{2}$ dialyser. The blood flow rate was standardized at $300 \mathrm{ml} / \mathrm{min}$, and the dialysate flow rate standardized at $500 \mathrm{ml} / \mathrm{min}$.
Table I Physical characteristics and co-morbidity of the study population

\begin{tabular}{|c|c|c|c|}
\hline Group & Gender & Age (years) & Co-morbidity \\
\hline \multicolumn{4}{|c|}{ CAPD patients } \\
\hline I & Male & 59 & Peripheral vascular disease (I) \\
\hline 2 & Female & 65 & None $(0)$ \\
\hline 3 & Male & 61 & Ischaemic heart disease (I) \\
\hline 4 & Male & 50 & Insulin-dependent diabetes mellitus (I) \\
\hline 5 & Female & 40 & None $(0)$ \\
\hline 6 & Male & 70 & $\begin{array}{l}\text { Ischaemic heart disease and left } \\
\text { ventricular dysfunction (2) }\end{array}$ \\
\hline 7 & Female & 55 & None $(0)$ \\
\hline 8 & Male & 63 & $\begin{array}{l}\text { Peripheral vascular disease, insulin- } \\
\text { dependent diabetes mellitus and } \\
\text { asthma (3) }\end{array}$ \\
\hline 9 & Male & 44 & Asthma (I) \\
\hline 10 & Female & 67 & Insulin-dependent diabetes mellitus (I) \\
\hline II & Male & 37 & Asthma (I) \\
\hline 12 & Female & 51 & None $(0)$ \\
\hline \multicolumn{4}{|c|}{ HD patients } \\
\hline I & Male & 74 & Ischaemic heart disease (I) \\
\hline 2 & Female & 76 & $\begin{array}{l}\text { Ischaemic heart disease and periphera } \\
\text { vascular disease (2) }\end{array}$ \\
\hline 3 & Female & 69 & Peripheral vascular disease $(\mathrm{I})$ \\
\hline 4 & Male & 53 & None $(0)$ \\
\hline 5 & Male & 74 & Peripheral vascular disease (I) \\
\hline 6 & Male & 48 & None $(0)$ \\
\hline 7 & Male & 44 & Left ventricular dysfunction $(I)$ \\
\hline 8 & Male & 55 & None $(0)$ \\
\hline 9 & Male & 71 & Ischaemic heart disease (I) \\
\hline 10 & Male & 35 & Asthma (I) \\
\hline II & Male & 70 & None $(0)$ \\
\hline 12 & Male & 71 & Arthritis (I) \\
\hline
\end{tabular}

None of the RFPs had used any corticosteroids or other drug known to induce muscle catabolism at the time of biopsy. The co-morbidity level of the RFPs was 0.7 (range, 0-3) and 0.8 (range, 0-2) for the CAPD and HD patients respectively (Table 1 ).

Seven patients from the CAPD group and nine patients from the $\mathrm{HD}$ group were treated with $\mathrm{r}-\mathrm{HuEPO}$ [recombinant human erythropoietin; $5000 \pm 1700$ IU (international units)/week for CAPD and $6000 \pm$ $2300 \mathrm{IU} /$ week for HD; EPREX; Janssen-cilag]. All of the HD patients were treated with heparin $(3000 \pm 1200 \mathrm{IU})$ during HD in order to prevent blood clotting. Seven patients from the CAPD group and three patients from the HD group were treated with $\beta$-adrenergic blockers.

All of the patients were given both an oral and written explanation of the purpose and procedures of the study prior to participation and provided written informed consent. All procedures were approved by the North Staffordshire Hospital Medical Ethics Committee. 


\section{Muscle biopsy}

A muscle biopsy (100-200 mg of wet tissue) for histochemical and quantitative enzymic analysis was taken from the medial head of the right gastrocnemius muscle of each RFP using the conchotome technique. The biopsy specimen was kept moist on a piece of saline-moistened gauze. The biopsy was cut into two parts at right angles in relation to the direction of muscle fibres, one part was used for histology/histochemistry analysis and the remainder for gel electrophoretic determination of $\mathrm{MyHC}$ (myosin heavy chain) composition.

\section{Histological and histochemical study}

The biopsy material was rapidly frozen in isopentane $\left(-155^{\circ} \mathrm{C}\right)$ for $10 \mathrm{~s}$ and stored in liquid nitrogen. Serial sections of the samples were obtained by cutting transverse sections of the biopsy $(10 \mu \mathrm{m}$ thickness in a cryostat; Leica cm 1800) at $-25^{\circ} \mathrm{C}$ and processed for histological staining.

The histochemical stains used were haematoxylin and eosin, Harris's haematoxylin [7] for morphological examination, acid-labile myofibrillar ATPase [8] preincubated at $\mathrm{pH} 4.40$ and 4.75 to determine the percentage of type I, IIa and IIx fibres, $\alpha$-amylase-PAS (periodic acid Schiff reagent) [9] for capillary density and the diaminobenzidine method for cytochrome $c$ oxidase activity [10]. The morphometric analysis was semi-automatic and performed with a camera (E.A.S.Y. 429K) connected to a light-microscope (Zeiss axioskop) and digitizer (Mitsubishi: Video Copy Processor, Herolab: molecular technique software) connected to a PC. The quantification of the cytochrome $c$ oxidase enzyme was performed with IBAS system (IBAS 2.0, Kontron Electronik). This quantification procedure has been described previously [11].

CSA (cross-sectional area) and circumference were calculated from a minimum of 50 fibres from type I and type IIa fibres and up to 50 fibres for type IIx, dependent upon the availability of the type IIx fibres. The fibre type distribution was determined from sections stained for myofibrillar ATPase and approx. 250 fibres for each sample were measured. Morphometric analysis of the biopsy was performed without prior knowledge of the group origin.

\section{Atrophy threshold}

In the absence of comparable control data, we classified as atrophic all those fibres with a CSA below a cut-off criterion of $2 \times$ S.D. of the mean CSA for the given fibre type and subject. This was essentially based on the atrophy factor calculations proposed by Brook and Engel [12]. According to Brook and Engel [12], the S.D. of a healthy individual's mean fibre CSA is always $\leqslant 0.25$ of the mean CSA for a given fibre type. Moreover, according to the same authors, the further fibres lie on the edges of the fibre size frequency distribution histogram the more important they are in order to calculate the atrophy level. Therefore we decided that $2 \times$ S.D. would provide us with an appropriate range that safely excluded what can be considered normal size fibres, but included the atrophic 'outer-range' distribution fibres.

\section{Capillary profile}

Capillaries were quantified manually from photographs taken from the previously described image analysis system. An area containing at least 150 fibres in each section was selected for the capillary counting. Analysis of capillary profiles included $\mathrm{C} / \mathrm{F}$ (capillary/fibre ratio), $\mathrm{CD} / \mathrm{mm}^{2}$ (capillary density $/ \mathrm{mm}^{2}$ of muscle tissue), CC/F (capillary contact/fibre), DD (diffusion distance) and ICD (intercapillary distance). All the above analyses were derived from direct measurements. DD was calculated from the mean fibre diameter divided by two. The ICD was calculated from the mean fibre circumference divided by the mean CC/F for each patient. All the capillary measurements were determined from 100 fibres, except the $\mathrm{CD} / \mathrm{mm}^{2}$, which included all the fibres within a specified area $\left(1 \mathrm{~mm}^{2}\right)$. All transversely cut capillaries were counted and, if a capillary was sectioned longitudinally, it was counted as one each time it crossed a junction between three or more muscle fibres [9].

\section{MyHC analysis}

The proportion of $\mathrm{MyHC}$ isoforms present in the whole muscle sample was determined as follows. Muscle specimens $(30-50 \mathrm{mg}$ ) were homogenized $\{1 \mathrm{mg}$ of tissue/ $10 \mu \mathrm{l}$ of buffer solution [10\% glycerol (w/v), $5 \%(\mathrm{w} / \mathrm{v})$ 2-mercaptoethanol, $2.3 \%(\mathrm{w} / \mathrm{v}) \mathrm{SDS}, 62.5 \mathrm{mM}$ Tris/HCl ( $\mathrm{pH}$ 6.8) and $0.001 \%(\mathrm{w} / \mathrm{v})$ Bromophenol Blue]\} and incubated at $80^{\circ} \mathrm{C}$ for $10 \mathrm{~min}$. Samples were then centrifuged at $12000 \mathrm{~g}$ for $5 \mathrm{~min}$ at $4^{\circ} \mathrm{C}$. The supernatant fractions were collected and stored separately $\left(-80^{\circ} \mathrm{C}\right)$ and analysed later by SDS/PAGE.

Vertical PAGE ( $0.75 \mathrm{~mm}$ thickness gels) in the presence of SDS was performed according to the methods of Talmadge and Roy [13]. MyHC was analysed in high glycerol-containing gels $(30 \%, \mathrm{w} / \mathrm{v})$. MyHC isoforms from the gastrocnemius muscle were resolved into three separate bands, MyHC I and IIa and IIx, in 8 and $2 \%$ $(\mathrm{w} / \mathrm{v})$ polyacrylamide for separating and stacking gels respectively. The percentage of acrylamide and bisacrylamide in the stock solution was 40:1. The gels were run for approx. $22 \mathrm{~h}$ at a constant current of $20 \mathrm{~mA}$ and at a temperature of $4{ }^{\circ} \mathrm{C}$. The relative content of $\mathrm{MyHC}$ isoforms was determined by densitometric methods using Coomassie-Blue-stained gels, and the protein bands were identified according to their apparent molecular mass compared with those of high-molecular-mass protein markers (Sigma). The densitometric system used was based on Herolab software as described above, and the coefficient of variation of the gel analysis was $7.5 \%$. 


\section{Nutritional assessment}

The nutritional status of the RFPs was assessed by the SGA (subjective global assessment) method using a seven point scale. The accuracy, reproducibility and validity of these methods have been shown previously in dialysis patients [14].

\section{Functional capacity assessment}

The daily activity level was determined by the '7-day activity recall' questionnaire administered by an experienced interviewer. This was based upon information about the time spent performing three levels of activity, including sleep time, during the previous 7 days [15]. All patients on this study were sedentary upon entering the study and did not engage in any regular physical activity. Functional capacity was assessed using a variety of objective measures, including (i) time to perform five sitto-stand-to-sit cycles (STS-5), (ii) number of sit-to-stand cycles achieved in $60 \mathrm{~s}$ (STS-60), and (iii) a previously validated corridor walking, stair climbing and descent test (NSRI). The validity and short-term reliability of this battery of tests has been established previously [16].

\section{Blood variables}

Blood samples were taken from HD patients on a nondialysis day and from CAPD patients $2 \mathrm{~h}$ after the change. For both dialysis groups, blood was used for measurement of urea creatinine mobilization, albumin concentration, mean venous $\mathrm{tCO}_{2}$ (total $\mathrm{CO}_{2}$ ), haemoglobin and PTH (parathyroid hormone).

\section{Statistical analysis}

All analyses were carried out by using the statistical package SPSS 9.0 for Windows (SPSS, Chicago, IL, U.S.A.). Standard descriptive statistics, consisting of mean and S.D., were used to characterize the subject population. A Mann-Whitney test was used to examine differences in the variable effects between and within groups respectively. The effect of length of dialysis treatments were assessed as covariate factors in CSA and capillary parameters. An $\alpha$ level of $P \leqslant 0.05$ was selected to indicate statistical significance.

\section{RESULTS}

\section{Patients}

The physical characteristics and co-morbidity of the study population are shown in Table 1 . There were no differences in age and gender between the two groups $(P>0.05)$. SGA indicated that three CAPD and two HD patients were malnourished and were categorized in B grade on the SGA scale, although no difference in nutritional status was detectable between the groups $(P>0.05)$. The HD group had a significantly lower haemoglobin concentration $(P<0.05)$ and mean venous
Table 2 Clinical assessment of CAPD and HD patient groups

Values are means \pm S.D. ${ }^{*} P<0.05$ compared with $H D$ patients. $K \mathrm{t} / V$, efficiency of the dialysis therapy.

\begin{tabular}{lccc}
\hline & $\begin{array}{c}\text { Normal } \\
\text { range }\end{array}$ & $\begin{array}{c}\text { CAPD patients } \\
(n=\mathrm{I} 2)\end{array}$ & $\begin{array}{c}\text { HD patients } \\
(n=\mathrm{I} 2)\end{array}$ \\
\hline $\mathrm{Kt} / \mathrm{V}$ (Urea creatinine) & $<\mathrm{I.5}$ & $2.5 \pm \mathrm{I.3}$ & $1.5 \pm 0.3$ \\
Albumin concentration $(\mathrm{g} / \mathrm{dl})$ & $35-50$ & $39 \pm 5$ & $39 \pm 4$ \\
Haemoglobin $(\mathrm{g} / \mathrm{dl})$ & $13-18$ & $12.6 \pm 1.3^{*}$ & $11.3 \pm 0.9$ \\
Mean venous $\mathrm{t} \mathrm{CO}_{2}(\mathrm{mmol})$ & $24-32$ & $26 \pm 4^{*}$ & $22 \pm 2$ \\
PTH (pmol/l) & $6-20$ & $22 \pm 20$ & $8.4 \pm 10$ \\
\hline
\end{tabular}

Table 3 Fibre type distribution and MyHC content determined from histochemistry and SDS/PAGE

Values are mean \pm S.D. No significant differences were observed between the two groups.

\begin{tabular}{lll}
\hline & CAPD patients $(n=12)$ & HD patients $(n=12)$ \\
\hline Fibre type & & \\
Type I (\%) & $59 \pm 12$ & $60 \pm 18$ \\
Type Ila (\%) & $30 \pm 11$ & $33 \pm 14$ \\
Type Ilx (\%) & $11 \pm 10$ & $7 \pm 7$ \\
MyHC content & & \\
MyHC I (\%) & $61 \pm 16$ & $60 \pm 15$ \\
MyHC Ila (\%) & $23 \pm 10$ & $24 \pm 13$ \\
MyHC IIx (\%) & $16 \pm 10$ & $16 \pm 6$ \\
\hline
\end{tabular}

$\mathrm{tCO}_{2}(P<0.01)$ than the CAPD group (Table 2). No differences between groups were found with respect to albumin or PTH concentration $(P>0.05)$.

\section{Muscle fibre type composition: MyHC isoform composition}

In the present study, no differences were found between the two groups with regards to fibre type distribution and $\mathrm{MyHC}$ isoform expression (Table 3).

\section{Muscle fibre CSA}

In the CAPD group, the mean CSA for type I fibres was 20 and $30 \%$ larger than type IIa and IIx fibres respectively (Figure 1). In the HD group, there was no significant difference between the mean CSA of the type I, IIa and IIx fibres. Although the mean CSA for each fibre type and for the combined weighted CSA for all fibre types was smaller in the CAPD compared with HD group, none of these differences was statistically significant (Figure 1). Regarding the percentage of atrophic fibres found in the two groups, no significant differences were observed between the two groups (Table 4).

\section{Capillary profile}

$\mathrm{CD} / \mathrm{mm}^{2}$ was not different between groups $(290 \pm 110$ compared with $300 \pm 77 \mathrm{CD} / \mathrm{mm}^{2}$ in the $\mathrm{HD}$ and 


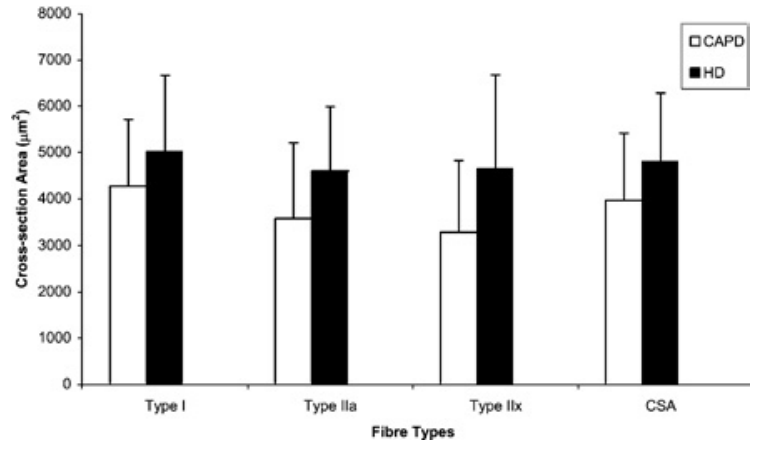

Figure I CSA of the different fibres types in CAPD $(n=12)$ $\overline{\text { and HD }}(n=12)$ patients

Values are means \pm S.D. CSA, combined weighted CSA.

Table 4 Percentage of fibres classified as atrophic for the CAPD and HD patient groups

Values are means \pm S.D. No significant differences were found between the groups. MCSA, mean CSA.

\begin{tabular}{lll}
\hline Atrophic fibres & CAPD patients $(n=12)$ & HD patients $(n=12)$ \\
\hline Type I (\%) & $55 \pm 13 \%$ & $44 \pm 21 \%$ \\
Type Ila (\%) & $63 \pm 9 \%$ & $47 \pm 25 \%$ \\
Type IIx (\%) & $60 \pm 16 \%$ & $59 \pm 22 \%$ \\
MCSA (\%) & $14 \pm 11 \%$ & $12 \pm 14 \%$ \\
\hline
\end{tabular}

CAPD groups respectively). However, when expressed in capillaries/fibre, the HD group had a $19 \%$ higher C/F value than the CAPD group $(1.9 \pm 0.4$ compared with $1.6 \pm 0.2$ respectively; $P<0.05)$. As a result, $\mathrm{CC} / \mathrm{F}$ was also higher in the HD group compared with the CAPD group (4.1 \pm 0.6 compared with $3.1 \pm 0.6$ respectively; $P<0.01)$.

No statistical differences between the HD and CAPD groups were found in measurements of the calculated DDs ( $34 \pm 5$ and $31 \pm 6 \mu \mathrm{m}$ respectively). ICD was $70 \pm 16$ and $81 \pm 21 \mu \mathrm{m}$ in the HD and CAPD groups respectively. In neither $\mathrm{HD}$ nor CAPD groups was there a relationship between the mean fibre CSA and CC/F. However, it should be noted that all of the values for the $\mathrm{HD}$ group for $\mathrm{CC} / \mathrm{F}$ independent of fibre CSA lie above the regression line of CAPD (Figure 2).

\section{Cytochrome c oxidase}

The cytochrome $c$ oxidase activity was higher in the type II fibres of the $\mathrm{HD}(n=11)$ compared with the $\operatorname{CAPD}(n=7)$ patients $(0.20 \pm 0.04$ compared with $0.15 \pm$ 0.02 IU respectively; $P<0.05)$. However, no difference was seen in the cytochrome $c$ oxidase activity in the type II fibres between the two groups $(0.30 \pm 0.05 \mathrm{IU}$ in the HD group compared with $0.30 \pm 0.06 \mathrm{IU}$ in the CAPD group).

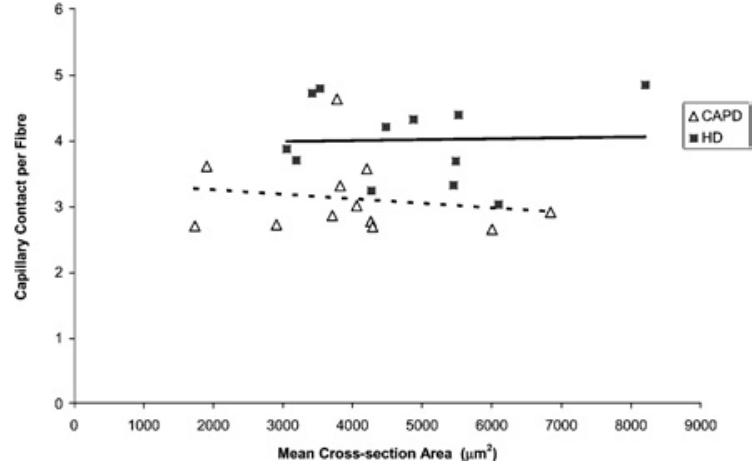

Figure 2 Scatter plot and regression for individual data points to show the distribution of CC/F and mean CSA in CAPD $(n=12)$ and HD $(n=12)$ patients

\section{Morphological features}

The proportion of fibres with central located nuclei was within the normal range $(\geqslant 5 \%)$ for all groups. In the CAPD group, the proportion of fibres with central nuclei was $4.4 \pm 2.4 \%$ of the total fibre number, and in the HD group it was $3.9 \pm 2.6 \%$. These values were not significantly different between the groups $(P>0.05)$.

\section{Physical activity status}

No differences were observed in daily activity level between the two renal failure groups $(2750 \pm 600$ and $2750 \pm 610 \mathrm{kcal} / \mathrm{day}$ for the CAPD and HD groups respectively; $P>0.05$; where $1 \mathrm{kcal} \equiv 4.184 \mathrm{~kJ}$ ). Similarly, there were no differences detected in functional capacity as assessed by STS-5 (13.1 \pm 3.8 compared with $13 \pm 3.5 \mathrm{~s}$ for the CAPD and HD groups respectively), STS-60 (21.4 \pm 8 compared with $21.7 \pm 7$ rep for the CAPD and HD groups respectively; $P>0.05$ ) or the walking test $(88 \pm 26 \mathrm{~s}$ compared with $85 \pm 17 \mathrm{~s}$ for the CAPD and HD groups respectively; $P>0.05$ ).

\section{DISCUSSION}

The present study set out to test the hypothesis that muscle morphological indices of functional status would be improved in patients receiving CAPD compared with those receiving HD.

In contrast with the initial hypothesis, no difference was found in muscle fibre type distribution or fibre size. Even more surprisingly, and counterintuitively, locomotory muscle capillarization, as measured by $\mathrm{C} / \mathrm{F}$ or $\mathrm{CC} / \mathrm{F}$, was significantly greater in a group of RFPs being treated with $\mathrm{HD}$ compared with those treated with CAPD. Furthermore, the enhanced capillarization in the HD group was also associated with a significantly higher level of cytochrome $c$ oxidase activity in type II fibres.

Both dialysis populations were similar in terms of age, gender, physical activity, nutritional status and PTH 
levels. However, the HD group had fewer females compared with the CAPD group, and it is recognized that gender may affect muscle fibre size such that young males have been reported to have larger type I, IIa and IIx muscle fibres (19, 59 and $66 \%$ larger respectively) compared with young females (for example, see [17]). In contrast with these findings for a younger population, we found no significant difference in the weighted mean CSA for all muscle fibres between our older males and females. There were no statistically significant differences in CSA between the CAPD and HD groups.

Renal failure has been shown to be associated with atrophy of skeletal muscle, a condition commonly described as uraemic myopathy [3-6]. In the present study, we have compared the muscle morphology in HD and CAPD patients. The fibre type percentage distribution was similar between the two groups, with type I fibres being the predominant fibre type. These data are in agreement with other studies on gastrocnemius muscle from RFPs [3] and healthy age-matched individuals [18]. In healthy subjects, it has often been observed that type II fibres are slightly larger in CSA than type I fibres [19]. In the CAPD group, we found a reversal of this pattern, with type II fibres being significantly smaller than type I fibres by approx. $20-30 \%$. It is possible that this represents an adaptation to the underlying pathology and may be related to the inadequate nutrient supply consequent upon a compromised microvasculature. It is interesting that this apparent pathology-related 'reversal' of the normal hierarchy of CSA was not seen in the HD group (mean CSA values differing by only approx. 5-8\%, which was not statistically significant).

In our study, the HD group appeared more anaemic and more metabolically acidotic than the CAPD group $(P<0.05)$ (Table 2$)$, and these could be two contributory factors to explain the inter-group differences found in capillarization $(\mathrm{CC} / \mathrm{F}$ and $\mathrm{C} / \mathrm{F})$. Hypoxia has been considered to be a stimulus to increase oxidative enzyme activity (cytochrome $c$ and succinate dehydrogenase) and increase the concentration of aerobic enzymes found in ischaemic muscles [20]. Our findings in the present study from the analysis of cytochrome $c$ oxidase showed that type II glycolytic fibres of HD patients did indeed have elevated enzyme activity levels, which were higher than the CAPD group. Hudlicka et al. [21] suggested that longterm hypoxia could be a stimulus for capillary growth in both skeletal and cardiac muscles, where it could stimulate the release of macrophage-derived growth factors. Although, we do not have direct evidence of tissue hypoxia, it is possible that, due to chronic impairment in blood oxygen carrying capacity, the RFPs could have mimicked the characteristics of ischaemic muscles as a consequence of anaemia. It is interesting to note that local oxygen concentration regulates VEGF (vascular endothelial growth factor) expression and hypoxia appears to upregulate receptors for VEGF. VEGF is a potent stimulus for angiogenesis and has been found to be elevated in the ischaemic limb of rabbits and in ischaemic myocardium [21]. Hudlicka et al. [21] have also proposed that a low $\mathrm{pH}$ could trigger activation of endothelial cell growth factors involved in capillary growth and angiogenesis. Since the HD patients tended to be both acidotic and anaemic (Table 2), these two factors in combination could stimulate angiogenesis.

An unexpected, but major, finding was that the HD group had $20-30 \%$ better capillarization, assessed in terms of $\mathrm{CC} / \mathrm{F}$ and $\mathrm{C} / \mathrm{F}$, compared with the CAPD group. In assessing the measurements of capillarity, it is important to remember that mitochondria are predominantly located around the perimeter of the muscle fibre and, hence, the distance between capillaries may be a more discriminating measure of the structural competence of the microvasculature rather than simple capillary density when expressed as $\mathrm{CD} / \mathrm{mm}^{2} \mathrm{CSA}$. Indeed, in the present study, there was no difference in capillary density between the CAPD and HD groups, despite the greater number of capillaries per fibre and $\mathrm{CC} / \mathrm{F}$ in the $\mathrm{HD}$ group. This apparently anomalous result is the direct consequence of the trend towards larger muscle fibres in the $\mathrm{HD}$ group, thus diluting the degree of capillarization when expressed in $\mathrm{CD} / \mathrm{mm}^{2}$. Using the preferred measure of ICD, which might reflect better the distance between capillary and mitochondria around the perimeter of the fibre, the calculated mean value is $10 \%$ higher in the HD group, although, due to the large variability, this still fails to reach conventional levels of significance. Nevertheless, it should be realised that this also represents, at the very least, a preservation of microvascular competence in the HD group, and that this is associated with a more normal pattern of fibre type CSA (in terms of relative mean CSA of different fibre types) and better oxidative potential as reflected in the measure of cytochrome $c$ oxidase. Consistent with this general picture of better preserved morphometric indices of muscle function in the HD patients, Figure 2 shows that their individual data points for $\mathrm{CC} / \mathrm{F}$ in relation to the fibre CSA all lie above the regression line for the CAPD patients.

The better-capillarized fibres in the HD patients did not appear to be the result of different levels of habitual physical activity or functional capacity. One study [22], however, suggested that capillary measurements should be corrected for mean fibre CSA. This does not appear to be a significant factor affecting the capillary bed in our present study, since there was no relationship between CSA and CC/F between the two groups (Figure 2). The enhanced capillarization might, however, be associated with the use of heparin in the HD group combined with lower haemoglobin levels and lower mean venous $\mathrm{tCO}_{2}$ and given similar habitual physical activity levels in both groups.

RFPs undergoing HD therapy receive about 20006000 IU of heparin three times a week in order to avoid 
blood coagulation when dialysed by an artificial kidney. Heparin has been suggested as a primary factor involved in angiogenesis [21]. In 1982, Taylor and Folkman [23] showed that heparin acts as a positive regulator of angiogenesis by trapping growth factors near to the cell surface and then binding to their receptors. However, heparin and/or heparan sulphate are unable to trigger angiogenesis by themselves, but act as a positive modulator (enhancer or amplifier) of angiogenic processes triggered by other stimuli, such hypoxia and exercise [24]. Fujita et al. [24] showed that heparin treatment alone without exercise did not improve myocardial ischaemia, whereas heparin administration combined with exercise did result in improvements.

It is conceivable, therefore, to assume that the increased number of capillaries $(\mathrm{CC} / \mathrm{F})$ in the muscle of the HD group could be a consequence of the angiogenic and growth effect of heparin administration, in combination with mild anaemia and acidosis, in the presence of similar levels of daily physical activity.

In conclusion, we have found that patients on HD therapy have enhanced capillarization, increased activity of cytochrome $c$ oxidase and a trend for larger muscle CSA of the locomotory muscles compared with the RFPs counterparts receiving CAPD therapy. Future studies involving this population should take into account that patients receiving different dialysis treatments experience different muscle characteristics.

\section{ACKNOWLEDGMENTS}

G. S. K. was supported by the Greek State Scholarship Foundation (IKY) (Grant No 11296). We thank Dr A. Webb and Dr R. Asghar at Staffordshire Hospital for providing us with the muscle biopsies as well as Mrs K. Pugh-Clarke for her assistance in data collection.

\section{REFERENCES}

1 Gokal, R., Figueras, M., Ollé, A., Rovira, J. and Badia, X. (1999) Outcomes in peritoneal dialysis and haemodialysis: a comparative assessment of survival and quality of life. Nephrol., Dial., Transplant. 14 (Suppl. 6), 24-30

2 Koufaki, P., Mercer, T. H. and Naish, P. F. (2002)

Dialysis does not affect exercise intolerance of patients with end stage renal disease. Clin. Exercise Physiol. 3, 154-160

3 Ahonen, R. E. (1980) Light microscopic study of striated muscle in ureamia. Acta Neuropathologica 49, 51-55

4 Fahal, H. I., Bell, G. M., Bone, J. M. and Edwards, R. H. T. (1997) Physiological abnormalities of skeletal muscle in dialysis patients. Nephrol., Dial., Transplant. 12, 119-127
5 Kouidi, E., Albani, M., Natsis, K. et al. (1998) The effects of exercise training on muscle atrophy in haemodialysis patients. Nephrol., Dial., Transplant. 13, 685-699

6 Sakkas, G. K., Ball, D., Mercer, T. H., Sargeant, A. J., Tolfrey, K. and Naish, P. F. (2003) Atrophy of non-locomotor muscle in patients with end stage renal failure. Nephrol., Dial., Transplant 18, 2074-2081

7 Stevens, A. and Wilson, I. (1996) The haematoxylins and eosin. In Theory and Practice of Histological Techniques, chapter 6 (Bancroft, J. D. and Stevens, A., eds.), pp. 99-102, Churchill Livingstone, Edinburgh

8 Brook, M. H. and Kaiser, K. K. (1969) Some comments on the histochemical characterisation of muscle adenosine triphosphatase. J. Histochem. Cytochem. 17, 431-432

9 Andersen, P. (1975) Capillary density in skeletal muscle of man. Acta Physiol. Scand. 95, 203-205

10 Seligman, A. M., Karnovsky, M. J., Wasserkrug, H. L. and Hanker, J. S. (1968) Nondroplet ultrastructural demonstration of cytochrome oxidase activity with a polymerizing osmiophilic reagent, diaminobenzidine (DAB). J. Cell Biol. 38, 1-14

11 Sant'Ana Pereira, J. A. A., Wessels, A., Nytmans, L., Moorman, A. F. M. and Sargeant, A. J. (1995) New method for the accurate characterisation of single human skeletal muscle fibres demonstrates a relation between mATPase and $\mathrm{MyHC}$ expression in pure and hybrid fibre types. J. Muscle Res. Cell Motil. 16, 21-34

12 Brook, M. H. and Engel, W. K. (1969) The histographic analysis of human muscle biopsies with regards to fibre types. 1. Adult male and female. Neurology 19, 221-233

13 Talmadge, R. J. and Roy, R. R. (1993) Electorophoretic separation of rat skeletal muscle myosin heavy-chain isoforms. J. Appl. Physiol. 75, 2337-2340

14 Enia, G., Sicuso, C., Alati, G. and Zoccali, C. (1993) Subjective global assessment of nutrition in dialysis patients. Nephrol., Dial., Transplant. 8, 1094-1098

15 Blair, S., Haskell, W., Ho, P. et al. (1985) Assessment of habitual physical activity by a seven day recall in a community survey and controlled experiments.

Am. J. Epidemiol. 122, 794-804

16 Mercer, T. H., Naish, P. F., Gleeson, N. P., Wilcock, J. E. and Crawford, C. (1998) Development of a walking test for the assessment of functional capacity in non-anaemic maintenance dialysis patients. Nephrol., Dial., Transplant. 13, 2023-2026

17 Staron, R. S., Hagerman, F. C., Hikida, R. S. et al. (2000) Fibre type composition of the vastus lateralis muscle of young men and women. J. Histochem. Cytochem. 48, 623-629

18 Coggan, A. R., Spina, R. J., King, D. S. et al. (1992) Skeletal muscle adaptation to endurance training in 60- to 70 -yr-old men and women. J. Appl. Physiol. 72, 1780-1786

19 Staron, R. S., Hagerman, F. C., Hikida, R. S. et al. (2000) Fibre type composition of the vastus lateralis muscle of young men and women. J. Histochem. Cytochem. 48, 623-629

20 Hudlicka, O. (1991) What makes blood vessels grow? J. Physiol. (Cambridge, U.K.) 444, 1-24

21 Hudlicka, O., Brown, M. and Egginton, S. (1992) Angiogenesis in skeletal and cardiac muscle. Physiol. Rev. 72, 369-417

22 Andersen, P. and Henriksson, J. (1977) Capillary supply of the quadriceps femoris muscle of man: adaptive response to exercise. J. Physiol. (Cambridge, U.K.) 270, 677-690

23 Taylor, S. and Folkman, J. (1982) Protamine is an inhibitor of angiogenesis. Nature (London) 297, 307-312

24 Fujita, M., Yamanishi, K., Kirai, T., Ohno, A., Miwa, K. and Sasayama, S. (1991) Comparative effect of heparin treatment with and without strenuous exercise on treadmill capacity in patients with stable effort angina. Am. Heart J. 122, 453-457 